\title{
Inconstitucionalidad de los Indultos por Crímenes de Lesa Humanidad. Comentarios al Fallo "Riveros"
}

Este comentario, junto a los

documentos que analiza,

está disponible en www.anuariocdh.uchile.cl

\author{
Jorge Pan*, Gianella Bardazano ${ }^{* *}$ y Diego Camaño Viera**
}

El 13 de julio de 2007 la Corte Suprema de la República Argentina declaró la inconstitucionalidad del Decreto 1002/89 dictado por el ex Presidente Menem, mediante el cual se indultó -entre muchos otros- a Santiago Riveros por su presunta participación en crímenes de lesa humanidad. Como consecuencia del indulto a comienzos de los 90, la justicia argentina había sobreseído a Riveros e incluso la Cámara Federal de San Martín se había pronunciado por la constitucionalidad del mismo Decreto 1002/89.

¿Cómo es posible que ahora, quince años después, la Corte Suprema habilite la reapertura de la causa, mediante la declaración de inconstitucionalidad del mismo Decreto que había indultado al imputado? Esta es la pregunta medular que debe responderse.

Dada la extensión y variedad de argumentos utilizados por la sentencia (sobre todo en las disidencias de los Ministros Fayt y Argibay), presentaremos una síntesis de los principales fundamentos, así como de las cuestiones jurídicas que consideramos más problemáticas. Teniendo en cuenta la extensión del trabajo, resulta imposible agotar los debates jurídicos que una sentencia de esta naturaleza plantea. Por eso, simplemente plantearemos algunos de los puntos álgidos, a modo de invitación para un debate más amplio.

\section{El contexto del fallo}

La sentencia de la Corte Suprema en este caso no es un acto aislado, sino que se inscribe en una serie de decisiones jurisdiccionales de distintas instancias que apuntan en la misma dirección: derribar cualquier obstáculo jurídico de derecho interno que impida el juzgamiento de crímenes internacionales cometidos durante la dictadura. Esto se obtuvo, en un primer momento, declarando la inconstitucionalidad de las leyes de impunidad y ahora, haciendo lo propio con los indultos presidenciales.

De los múltiples pronunciamientos en procesos penales y pedidos de extradición que transitan el mismo camino, cabe destacar la sentencia del 14 de julio de 2005 de la Corte Suprema, mediante la cual declaró inconstitucionales las leyes de obediencia debida y punto final en la causa contra Julio Héctor Simón. Dicho fallo además ratificó lo dispuesto por la ley 25.779 que en 2003 había anulado las referidas leyes, que impedían la persecución penal por estos hechos ${ }^{1}$.

\footnotetext{
* Abogado, Presidente del Instituto de Estudios Legales y Sociales del Uruguay (IELSUR), Miembro de la Comisión Internacional de Juristas (CIJ).

** Abogada, Profesora Adscripta y Asistente G.2 de Filosofía del Derecho de la Universidad de la República, integrante del Instituto de Estudios Legales y Sociales del Uruguay (IELSUR).

*** Abogado, Profesor Adjunto de Derecho Penal de la Universidad de la República, miembro del Consejo Directivo del Instituto de Estudios Legales y Sociales del Uruguay (IELSUR).

1 Para un ilustrativo comentario de esta sentencia ver FERNÁNDEZ VALLE, Mariano: “La Corte Suprema argentina frente al legado de la última dictadura militar: reseña del fallo Simón", en Anuario de Derechos Humanos N² 2, pp. 165 a 174. Centro de Derechos Humanos-Universidad de Chile, 2006. Accesible en www.anuariocdh.uchile.cl/
} 
En este contexto, la declaración de inconstitucionalidad de los indultos presidenciales abre nuevas puertas para la reapertura de otros procesos judiciales.

Independientemente de si las reaperturas de juicios son deseables o no, la trascendencia de las cuestiones jurídicas ventiladas plantea la necesidad de debatir sobre la sentencia, prestando especial atención a las disidencias de los Ministros Fayt y Argibay, dada la fortaleza de sus argumentos jurídicos.

\section{Los indultos presidenciales}

El inicio del primer gobierno de Menem se caracterizó por una serie de decisiones de indulto a favor de cientos de personas vinculadas con crímenes perpetrados durante el régimen de facto (aunque también abarcó a los "carapintadas" que se rebelaron contra el gobierno democrático hacia fines de 1987).

Señala Nino que "el 6 de octubre de 1989, Menem sancionó tres decretos que indultaron a casi cuatrocientas personas que se hallaban bajo proceso" [entre ellos el 1002/89, sobre el cual versa el fallo comentado]. "Esa medida era de una constitucionalidad cuestionable. El artículo 86 de la Constitución Argentina provee que el presidente puede firmar indultos, sólo en la medida en que sea coherente con el artículo 95 que prohíbe al presidente interferir en juicios aún pendientes" ${ }^{2}$. Por lo tanto, según Nino ese primer grupo de indultos era inconstitucional, "porque liberaron a personas que no habían sido condenadas aún" ${ }^{3}$.

Sobre fines de 1990 Menem decretó otro conjunto de indultos, entre cuyos beneficiarios se encontraban quienes habían sido condenados en el célebre "juicio a las juntas", así como también a jefes militares condenados por la conducción de la guerra de las Malvinas. Según Nino, estos indultos eran "constitucionalmente impecables" (por haber sido concedidos a personas condenadas) pero políticamente inconvenientes, "dado que había poca presión social para liberar a quienes fueron los mayores responsables por los abusos a los derechos humanos" ${ }^{4}$.

\section{Una causa judicial en dos etapas}

La causa judicial seguida contra Riveros tuvo una primera etapa que concluyó con el indulto concedido mediante el Decreto 1002/89, cuyo efecto jurídico fue el sobreseimiento definitivo del imputado. En 1989 la Cámara Federal de San Martín rechazó una petición de inconstitucionalidad del indulto por parte de las víctimas, quienes posteriormente presentaron un recurso extraordinario ante la Corte. Éste fue rechazado a fines de 1990 por razones formales, dejando firme el sobreseimiento.

En una segunda etapa, ante una nueva solicitud de inconstitucionalidad por parte de las víctimas, en el 2004 un Juez Federal declaró la inconstitucionalidad del Decreto presidencial de indulto (sobre la base de que los crímenes de lesa humanidad son "inindultables") y privó de efectos al sobreseimiento. En vía recursiva, la Cámara Federal de San Martín revocó la sentencia recurrida en base al principio constitucional de cosa juzgada. Según este órgano el sobreseimiento había quedado firme, generando derechos en favor del imputado. Asimismo, sostuvo

\footnotetext{
2 NINO, Carlos S.: Juicio al mal absoluto, p.159. Ariel, Bs.As., 2006.

3 NINO, ob.cit., p. 160. En el mismo sentido, BOVINO, Alberto y DULITZKY, Ariel: "No hay olvido" en No hay derecho, № 3, p.2. Bs.As, 1991.

4 NINO, ob.cit., p.160.
} 
la posición contraria a la de Nino, al afirmar que el indulto presidencial también puede ser acordado a un procesado.

Ante un nuevo recurso, en el 2006 la Cámara Nacional de Casación Penal revocó lo establecido por la Cámara Federal, sobre la base de la primacía del derecho de las víctimas y el deber del Estado de investigar crímenes de lesa humanidad, en relación a la garantía constitucional de cosa juzgada. También invocó el caso Kolk tramitado ante la Corte Europea, concluyendo que para el juzgamiento de crímenes de lesa humanidad no rigen limitaciones de espacio y tiempo, ni pueden dictarse indultos o leyes de prescripción. Citó diversos tratados sobre derechos humanos aprobados por la República Argentina tales como la Convención contra el Genocidio, la Convención Americana sobre Derechos Humanos y la Convención Interamericana contra la Tortura. Invocó el caso Barrios Altos de la Corte Interamericana y afirmó que sostener la cosa juzgada en este caso importa un "beneficio que no es otro que la misma detracción de derechos fundamentales de otros sujetos", a saber el derecho a "investigar las violaciones a atributos fundamentales de los seres humanos, determinar quiénes fueron responsables y aplicar las sanciones que correspondan" (párr.6 Considerando $1^{\circ}$ voto Argibay).

Finalmente, a mediados de 2007 la Corte Suprema confirmó el fallo de la Cámara Nacional, declarando la inconstitucionalidad del Decreto de indulto, con las disidencias de los Ministros Fayt y Argibay.

\section{III.A. El voto de la mayoría}

Los Ministros Lorenzetti, Highton, Maqueda y Zaffaroni entendieron que el indulto presidencial había sido inconstitucional.

Rechazan los argumentos esgrimidos por la Defensa de Riveros, a saber:

a) La violación a la garantía del Juez natural. La Defensa argumentaba que el caso era competencia de la justicia militar y no de la civil.

Al respecto, los Ministros señalaron que ya se habían pronunciado sobre esta materia en la sentencia del caso "Videla", indicando además que la justicia civil era competente en virtud de la obligación del Estado argentino de juzgar, por la jurisdicción común, los casos de desapariciones forzadas, luego de haber aprobado la Convención Interamericana Sobre Desaparición Forzada de Personas (art. IX).

b) La prohibición de la doble persecución penal.

Si bien los Ministros reconocieron el rango constitucional de la prohibición, rechazaron esta defensa afirmando que en este caso se estaba ante la comisión de delitos de lesa humanidad. Señalaron que el país asumió obligaciones establecidas en el derecho internacional humanitario y de los derechos humanos de: a) perseguir; b) investigar y, c) sancionar adecuadamente a los responsables de cometer delitos que constituyen graves violaciones a los derechos humanos.

Desde el reconocimiento de la dignidad humana y la igualdad entre todos los seres humanos, contenida en el Preámbulo de la Declaración Universal de Derechos Humanos, se ha construido una concepción del derecho internacional que procura excluir los crímenes internacionales cometidos en el ejercicio de funciones estatales.

El antiguo artículo 102 de la Constitución Nacional -actual 118, modificado por la reforma constitucional de 1994- reconoce el derecho de gentes, que hace a la existencia de un sistema de 
protección de los derechos de la persona, los cuales resultan obligatorios en forma independiente al consentimiento de las naciones que las vincula, y que es conocido actualmente dentro de ese proceso evolutivo como ius cogens.

La obligación de los magistrados en casos sobre violaciones a los derechos humanos consiste en respetar el ordenamiento jurídico interno, pero cuando se encuentra vigente un tratado de derechos humanos, "es obligación de los magistrados no sólo aplicar el Tratado, sino además la interpretación que del mismo ha realizado la Corte Interamericana", tomando como base el caso "Almonacid" (Considerando 21 de la sentencia).

Aun antes de la reforma constitucional de 1994, que reconoció expresamente la preeminencia del sistema internacional de protección de los derechos humanos, la Corte en 1992 en el fallo "Ekmedkjian" ya había sostenido que en toda cuestión referida a un tratado se debe seguir la jurisprudencia de los órganos encargados de interpretarlo (en el caso, la interpretación de la Convención Americana debe guiarse por la jurisprudencia de la Corte Interamericana).

Grosso modo, el voto mayoritario sostuvo que las garantías de cosa juzgada y ne bis in idem, según lo resuelto por la Corte Interamericana en los casos "Barrios Altos" y "Almonacid", no son excusa para que el Estado incumpla con su deber de investigación y sanción a los responsables de crímenes de lesa humanidad.

Además, se remitieron a los propios precedentes de la Corte Suprema en "Arancibia Clavel" y "Simón", y consideraron que no existía ninguna distinción jurídica entre los crímenes que se denuncian en la causa "Riveros" y los que dieron lugar a las citadas sentencias.

En definitiva, el indulto presidencial cercenó las obligaciones internacionales asumidas por la República Argentina de comprobar las denuncias por delitos de lesa humanidad, identificar a los responsables e imponer las sanciones correspondientes.

Al declararse la inconstitucionalidad del indulto, quedó habilitada la reanudación de la causa, que se encontraba clausurada hace aproximadamente quince años.

\section{III.B. La disidencia de Fayt}

La extensión y profundidad de los argumentos manejados por Fayt nos obligan a hacer una somera y selectiva presentación ${ }^{5}$. En primer lugar, cabe aclarar que el Ministro ya se había pronunciado en diversas causas en el mismo sentido, por lo que su opinión viene a reafirmar una posición que coherentemente mantiene desde hace largo tiempo.

El voto de disidencia comienza cuestionando la aplicación del principio de imprescriptibilidad, pues si bien la Convención sobre Imprescriptibilidad de Crímenes de Guerra y de Lesa Humanidad fue aprobada en 1968, recién fue ratificada en 1995. De este modo, contradice la aplicación retroactiva de la Convención, afirmada por la Corte Europea en el caso "Kolk", posición que cuenta con el aval de prestigiosa doctrina en la materia ${ }^{6}$. Si bien Fayt reconoce que buena parte de la doctrina sostiene la retroactividad (en base al propio texto de la Convención), afirma que a su juicio esto lesiona el principio constitucional de legalidad. Y agrega un curioso argumento político, según el cual su interpretación "procura detener el avance de los poderosos sobre los

5 Los argumentos sobre el principio de cosa juzgada los trataremos al analizar el voto de Argibay, dado que si bien la línea argumental de Fayt es más extensa, la razón sustancial es la misma.

6 CASSESE, Antonio: "Balancing the prosecution of crimes against humanity and non-retroactivity of criminal law. The Kolk and Kislyiy v. Estonia case before the ECHR" en Journal of International Criminal Justice, No4, pp. 410-418. Oxford University Press, 2006. 
asuntos internos de los más débiles [procurando] evitar que detrás de un aparente humanismo jurídico se permitan ejercicios coloniales de extensión de soberanía". Según Fayt, dicha tesis puede corroborarse observando "cuáles son a la fecha los países signatarios de la Convención" (Considerando 12 voto Fayt).

Otro argumento importante es el del "margen nacional de apreciación" según el cual los jueces de los Estados deben contar con un espacio lo suficientemente amplio a la hora de decidir si aplican o no las normas de derecho internacional, en especial sobre la base de los principios constitucionales. Esta doctrina proviene de la Corte Europea; y aunque la discordia cita en su apoyo la Opinión Consultiva 4/84 de la Corte Interamericana, bien vale tener presente que en el ámbito interamericano, la doctrina del margen de apreciación no ha merecido un grado de reconocimiento similar al del espacio europeo.

Por otra parte, sostiene que en el fallo Ekmedkjian, la Corte no afirmó la primacía del derecho internacional sobre el derecho interno, sino más bien la prioridad de aquel en relación a la ley. A partir de ahí desarrolla una serie de argumentos que intentan rescatar la superioridad jerárquica de la Constitución en relación a los tratados internacionales. Todo ello con el criterio rector de que por más graves que sean los hechos investigados, las garantías constitucionales básicas no pueden ser sacrificadas.

Otro punto importante es el cuestionamiento de Fayt a la invocación de la condición de norma de ius cogens de la imprescriptibilidad de los crímenes de lesa humanidad, que se ha utilizado sin el rigor necesario para habilitar su persecución penal, ignorando sus exactos alcances. Señala, inter alia, que la imprescriptibilidad no tendría carácter de ius cogens, afirmando elocuentemente que "la calificación del principio de imprescriptibilidad como norma ius cogens no tiene más base que la afirmación dogmática de quienes suscriben el fallo". Según Fayt "un importante y autorizado sector de internacionalistas" (que no cita) afirma que la imprescriptibilidad ni siquiera es un principio general de derecho internacional y no existe una práctica de los Estados que permita dar base a una norma de derecho consuetudinario, por lo que se trata de una "fundamentación aparente" (Considerando 22 voto Fayt).

Por otra parte afirma que de declararse constitucional la imprescriptibilidad de los crímenes de lesa humanidad, se afectaría el ne bis in idem, principio que no solamente impide que una persona sea condenada dos veces por el mismo hecho, "sino que basta para incurrir en la violación con que se la someta al riesgo -por medio de un nuevo proceso- de que pueda ser condenada", citando varios fallos anteriores de la Corte en el que se sostuvo este criterio (párr. 2 Considerando 28 voto Fayt).

Finalmente, un aspecto central en su posición es la legitimidad del uso del instituto del indulto presidencial incluso en relación a crímenes de lesa humanidad. A su juicio la concesión de indultos presidenciales "gozó de legitimidad, legalidad, validez y vigencia" (párr.2 Considerando 44 voto Fayt). Cita en su apoyo antiguos casos (de fines de siglo XIX y principios de siglo XX) de la Suprema Corte de los Estados Unidos en que se estableció que no se podía excluir de su ejercicio a cualquier clase de delincuentes. Y luego aclara que la reforma constitucional de 1994 solamente excluyó de la posibilidad del indulto "a aquellos que interrumpan la observancia de la Constitucional Nacional por actos de fuerza contra el orden institucional y el sistema democrático", pero sin que exista una distinción en base a la categoría de los delitos imputados.

Si bien en anteriores fallos la Corte desechó expresamente la posibilidad de indultar crímenes de lesa humanidad, Fayt sostiene que la Constitución admite el instituto para cualquier tipo de delito. Asimismo, cita otras experiencias - difícilmente asimilables- como la sudafricana, en la cual se utilizó el instrumento de las amnistías, señalando la importancia del derecho a la verdad, que "puede asegurarse sin necesidad de violentar las garantías del imputado sometido a proceso". 
Hacia el final de su voto, señala, en forma tan breve como representativa de su pensamiento, que los principios constitucionales "deben ser defendidos férreamente a fin de conjurar que el enfoque inevitablemente difuso y artificioso del derecho penal internacional conduzca a la destrucción de aquellos", remitiéndose a su propio voto en "Arancibia Clavel" (párr. final Considerando 61 voto Fayt).

\section{III.C. La disidencia de Argibay}

La disidencia parcial de la jueza Argibay explicita los límites constitucionales que afectan a la Corte Suprema, vinculados a lo que ésta puede efectivamente hacer (o lo que no puede hacer sin caer en un exceso de decisionismo ${ }^{7}$ ) para arribar a una solución orientada a la realización del ideal de justicia.

En efecto, pese a considerar que los indultos concedidos a personas procesadas son inconstitucionales ("nada hay que perdonar mientras no existe una condena que imponga pena"; párr.1 Considerando 5 voto Argibay), la disidencia parcial se apoya en la existencia de cosa juzgada respecto de la validez de los indultos, así como en el alcance que una sentencia pasada en autoridad de cosa juzgada despliega sobre la efectividad de la garantía ne bis in idem.

Entiende que la Corte Suprema había cerrado el debate en 1990 cuando rechazó los recursos extraordinarios en la misma causa en la cual se dicta la sentencia comentada. "Lo que está en juego en esta causa es [...] el principio de cosa juzgada y la prohibición de doble juzgamiento" (párr. 6 in fine, Considerando $5^{\circ}$, voto Argibay) que, señala claramente el voto, implica la prohibición de múltiple persecución penal, esto es, "no sólo veda la aplicación de una segunda pena por un mismo hecho sino también 'la exposición al riesgo de que ello ocurra' (Fallos: 314:377; 319:43; 321:1173, disidencia de los jueces Petracchi y Bossert y 321:2826, entre otros)" (párr.2, Considerando $4^{\circ}$ voto Argibay), lo cual remarca el carácter definitivo del sobreseimiento.

De acuerdo con los argumentos de la disidencia analizada, la morigeración de la certeza de la cosa juzgada constituye un preocupante precedente que conspira contra una concepción "razonable" del Poder Judicial, atendiendo a los arreglos institucionales establecidos en la Constitución Nacional. En especial, señala, que habilitaría la posibilidad de una revisión indefinida de las sentencias por futuros jueces que no compartieran sus fundamentos, lo cual aumentaría, creemos, la discrecionalidad de los tribunales y la contingencia de sus fallos. En ese sentido, sostiene: "Ni esta Corte, ni ningún otro tribunal, puede eludir los efectos de una decisión judicial firme sin negarse a sí mismo, es decir, sin poner las condiciones para que sus propios fallos sean también revocados en el futuro con argumentos contrarios, esto es, alegando su error, injusticia, etcétera" (párr. 3, considerando $6^{\circ}$ voto Argibay).

Nos interesa destacar y relacionar lo señalado en la disidencia respecto del aumento de la discrecionalidad y la contingencia de los fallos, esto es, el mero decisionismo, vinculado con el

\footnotetext{
Hablamos de decisionismo para referimos a aquellos casos en los cuales la solución depende de la elección entre principios inderrotables entre sí, donde la voluntad del juzgador pone en evidencia los límites de la racionalidad jurídica, o, en otras palabras, donde la voluntad del juzgador es determinante. En otras palabras, la solución del conflicto implica cierto sacrificio (en el caso, la atenuación de las garantías de cosa juzgada y ne bis in idem), ya que la elección de un principio supone dejar al otro de lado, supone dejar por el camino algo que se considera valioso (Lariguet, Guillermo; "Conflictos trágicos y derecho. Posibles desafíos", Doxa 27, 2004, p.320-322). En ese sentido, el constitucionalista y teórico del derecho italiano Guastini describe la ponderación entre principios constitucionales en conflicto en términos de una elección, que produce un sacrificio, y que se apoya en el juicio subjetivo de lo que a un juez le parece justo o menos injusto para el caso concreto: "consiste en el establecimiento de una jerarquía axiológica (...) establecida no por las propias fuentes, sino por el intérprete" (Guastini, Riccardo; Distinguiendo. Estudios de teoría y metateoría del derecho, Gedisa, Barcelona, 1999, p.170).
} 
funcionamiento del Poder Judicial y la consolidación del Estado de Derecho. Estos argumentos explicitan la tensión existente entre la compatibilización entre la evolución del derecho de gentes o el ius cogens y la plena vigencia de garantías constitucionales, también recogidas por diversos instrumentos internacionales sobre derechos humanos.

Es importante aclarar que el sobreseimiento y la correlativa extinción de la responsabilidad penal no implica la imposibilidad de investigar los hechos y la búsqueda de la verdad, en la medida que "se está tratando la situación de una sola persona, en una situación particular" (párr. 1, considerando $7^{\circ}$ voto Argibay), esto es, un sobreseimiento definitivo como consecuencia de la constitucionalidad del decreto de indulto resuelta en 1990.

\section{Reflexiones para el debate}

La sentencia se enmarca en los Ilamados principios emergentes del derecho penal internacional, y su lectura evidencia claramente dos posicionamientos jurídicos que, sin perjuicio de las complejidades que encierran, pueden resumirse en los siguientes términos:

a) el que da primacía a las garantías constitucionales por sobre las obligaciones de los Estados frente a la persecución penal de crímenes de lesa humanidad, aunque se comprometa la responsabilidad internacional del Estado;

b) el que da primacía a las obligaciones internacionales del Estado frente a estos crímenes, salvando su responsabilidad internacional, aun cuando esto implique una diferente comprensión del alcance de las garantías constitucionales.

Resulta imposible en este acotado espacio ingresar a las disquisiciones que conceptos como el ius cogens, la imprescriptibilidad o los diferentes alcances del principio de legalidad y de cosa juzgada en el ámbito interno e internacional requieren. Asimismo, habría que confrontar, por un lado, la utilización masiva del instituto del indulto y su procedencia en relación a crímenes de lesa humanidad, y por el otro, las garantías que hacen a la seguridad jurídica en un Estado de derecho.

En todo caso, son estos los fallos que plantean la necesidad de un debate robusto acerca de las implicancias jurídicas, morales y políticas de la persecución penal de crímenes de lesa humanidad, los fundamentos y los límites del poder punitivo en este ámbito. 